\title{
Author Correction: Myoblasts and macrophages are required for therapeutic morpholino antisense oligonucleotide delivery to dystrophic muscle
}

James S. Novak ${ }^{1,2,3}$, Marshall W. Hogarth', Jessica F. Boehler ${ }^{1,2}$, Marie Nearing ${ }^{1}$, Maria C. Vila ${ }^{1,2}$, Raul Heredia1, Alyson A. Fiorillo1,2,3, Aiping Zhang ${ }^{1}$, Yetrib Hathout 1,2,3,4, Eric P. Hoffman 1,2,3,4, Jyoti K. Jaiswal (1) 1,2,3, Kanneboyina Nagaraju ${ }^{1,2,3,4}$, Sebahattin Cirak ${ }^{1,5,6,7} \&$ Terence A. Partridge $e^{1,2,3}$

Nature Communications 8:941 10.1038/s41467-017-00924-7; Published online: 16 October 2017

In the original version of this Article, financial support was not fully acknowledged. The PDF and HTML versions of the Article have now been corrected to include support from the CRI Light Microscopy and Image Analysis Core.

Microscopic analysis for this study was conducted at the CRI Light Microscopy and Image Analysis Core, which is supported by CRI and the Intellectual and Developmental Disabilities Research Center Award (U54HD090257) through the National Institutes of Health NICHD.

Published online: 15 January 2018

ceproduction in any medium or format, as long as you give appropriate credit to the original author(s) and the source, provide a link to the Creative Commons license, and indicate if changes were made. The images or other third party material in this article are included in the article's Creative Commons license, unless indicated otherwise in a credit line to the material. If material is not included in the article's Creative Commons license and your intended use is not permitted by statutory regulation or exceeds the permitted use, you will need to obtain permission directly from the copyright holder. To view a copy of this license, visit http://creativecommons.org/licenses/by/4.0/.

(C) The Author(s) 2018

\footnotetext{
${ }^{1}$ Center for Genetic Medicine Research, Children's Research Institute, Children's National Health System, Washington, DC 20010, USA. ${ }^{2}$ Institute for Biomedical Sciences, The George Washington University School of Medicine and Health Sciences, Washington, DC 20052, USA. ${ }^{3}$ Department of Pediatrics, The George Washington University School of Medicine and Health Sciences, Washington, DC 20052, USA. ${ }^{4}$ Department of Pharmaceutical Sciences, School of Pharmacy and Pharmaceutical Sciences, Binghamton University, Binghamton, NY 13902, USA. ${ }^{5}$ Institute for Human Genetics, University Hospital Cologne, Cologne 50923, Germany. ${ }^{6}$ Department of Pediatrics, University Hospital Cologne, Cologne 50923, Germany. ${ }^{7}$ Center for Molecular Medicine, University of Cologne, Cologne 50931, Germany. Sebahattin Cirak and Terence A. Partridge contributed equally to this work. Correspondence and requests for materials should be addressed to T.A.P. (email: TPartridge@childrensnational.org)
} 